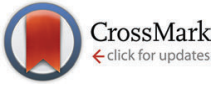

Cite this: Chem. Commun., 2016, 52,12326

Received 16th August 2016, Accepted 20th September 2016

DOI: $10.1039 / c 6 c c 06737 a$

www.rsc.org/chemcomm

\section{Spatially well-defined carbohydrate nanoplatforms: synthesis, characterization and lectin interaction study $\dagger$}

\author{
B. J. J. Timmer $\ddagger^{\mathrm{a}}$ M. Abellán Flos,$\ddagger^{\mathrm{b}}$ L. Mønster Jørgensen, ${ }^{\mathrm{C}}$ D. Proverbio, ${ }^{c}$ \\ S. Altun, ${ }^{c}$ O. Ramström, ${ }^{\star a}$ T. Aastrup ${ }^{\star c}$ and S. P. Vincent ${ }^{\star b}$
}

\begin{abstract}
Two novel dodecasubstituted carbohydrate nanoplatforms based on molecular Borromean rings and dodecaamine cages have been prepared for use in evaluating the importance of the spatial distribution of carbohydrates in their interaction with lectins. The binding affinities of the glyconanoplatforms were characterized using quartz crystal microbalance technology and compared with a monovalent reference and dodecaglycosylated fullerenes.
\end{abstract}

Carbohydrates act as carriers of information in living systems and play critical roles in regulation, modulation and adhesion processes. ${ }^{1}$ For efficient information transfer to occur, relatively strong interactions between carbohydrates and their cognate receptors are required; however, they are usually weak for monovalent saccharides. Nature addresses this effect by multivalent presentation of carbohydrates to enhance the affinity and selectivity in vivo, an effect referred to as the "cluster glycoside effect'. ${ }^{2}$ To unravel the processes in which carbohydrates are involved, it is essential to better understand this effect. For this purpose, a wide variety of multivalent glycosylated architectures have previously been synthesized and assessed, e.g., glycoclusters, glycodendrimers, glycopolymers and glyconanoparticles. ${ }^{3}$ However, in most of these platforms it is challenging to control the local density and spatial arrangement of the carbohydrate ligands. An intriguing nanoplatform which enables full control of spatial presentation is the fullerene: $\mathrm{a}_{60}$ truncated icosahedral core which can be hexafunctionalized to give a globular $T_{\mathrm{h}}$-symmetrical core with an octahedral substitution pattern. ${ }^{4}$ Carbohydrate functionalization of this core structure

\footnotetext{
${ }^{a}$ KTH - Royal Institute of Technology, Department of Chemistry, Organic Chemistry, Teknikringen 36, S-100 44 Stockholm, Sweden. E-mail: ramstrom@kth.se

${ }^{b}$ University of Namur, Départment de Chimie, Laboratoire de Chimie Bio-Organique, Rue de Bruxelles 61, B-5000 Namur, Belgium.E-mail: stephane.vincent@unamur.be ${ }^{c}$ Attana AB, Björnnäsvägen 21, SE-114 19 Stockholm, Sweden.

E-mail: teodor.aastrup@attana.com

$\dagger$ Electronic supplementary information (ESI) available: Experimental details, characterization data and copies of NMR $\left({ }^{1} \mathrm{H},{ }^{13} \mathrm{C}\right.$ and $\left.{ }^{19} \mathrm{~F}\right)$ and IR spectra. See DOI: $10.1039 / \mathrm{c} 6 \mathrm{cc} 06737 \mathrm{a}$

\# These authors contributed equally.
}

yields dodecavalent carbohydrate nanoplatforms, which have been widely studied with varying carbohydrate types, linker types and linker lengths. ${ }^{5}$

To further investigate the influence of the spatial arrangement of carbohydrates on multivalent recognition, new nanoplatforms with a high degree of symmetry in ligand presentation are desirable. A field offering access to such platforms is the field of constitutional dynamic chemistry (CDC). ${ }^{6}$ The thermodynamic and self-sorting nature of CDC allows for the high-yielding synthesis of complex multi-dimensional architectures from simple starting materials. ${ }^{7}$ Two interesting nanoplatform architectures that can be assembled using CDC are molecular Borromean rings (BRs) ${ }^{8}$ and dodecaamine cages. ${ }^{9}$ Derivatization of these core structures results in nanoplatforms with a high degree of symmetry in ligand presentation. ${ }^{10}$ Derivatization of Borromean rings yields 'globular' $S_{6}$-symmetrical core structures with a diameter of $24 \AA$ and an octahedral addition pattern of the ligands, whereas the derivatized dodecaamide cages have a $T_{\mathrm{d}}$-symmetrical core structure with a diameter of $20 \AA$ and an icosahedral addition pattern of the ligands (Fig. 1).

Herein, we report the synthesis of two novel carbohydrate nanoplatforms by carbohydrate functionalization of molecular Borromean rings and dodecaamide cages. The binding kinetics and thermodynamics of the carbohydrate nanoplatforms were assessed in real-time against the lectin concanavalin A (ConA) using quartz crystal microbalance (QCM) technology, ${ }^{11}$ and compared with previously known dodecaglycosylated fullerenes.

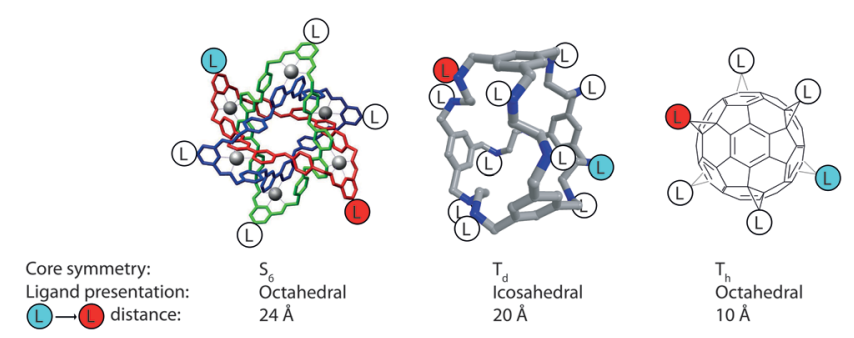

Fig. 1 Symmetry and size of nanoscaffolds. 

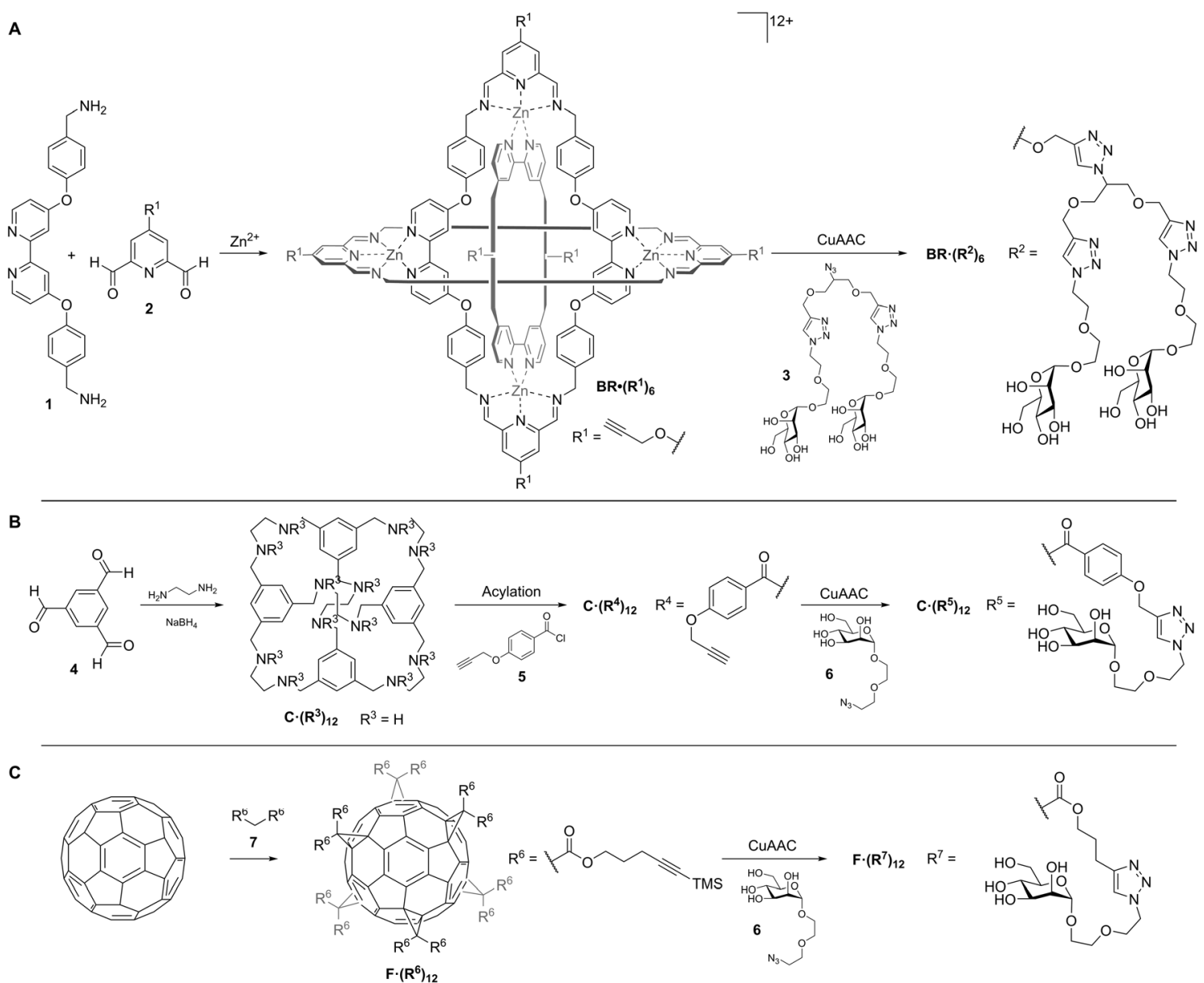

Fig. 2 Synthesis of dodecavalent glyconanoplatforms based on (A) molecular Borromean rings, (B) dodecaamine cages and (C) fullerenes.

In addition to the main objective of evaluating the influence of the spatial arrangement of carbohydrates on protein binding affinity, this is the first application of the molecular Borromeate scaffold in biomolecular recognition.

The preparation of the different carbohydrate nanoplatforms used in this study is illustrated in Fig. 2 ( $c f$. ESI $\dagger)$. The synthesis of molecular Borromeate BR. $\left(\mathbf{R}^{\mathbf{1}}\right)_{\mathbf{6}}$ was achieved by polycondensation of diamine $\mathbf{1}$ with alkyne-functionalized building block 2 in the presence of templating $\mathrm{Zn}^{\mathrm{II}}$ ions. $\mathrm{Cu}^{\mathrm{I}}$-catalyzed azide alkyne cycloaddition (CuAAC) between BR.( $\left.\mathbf{R}^{\mathbf{1}}\right)_{\mathbf{6}}$ and divalent azido-functionalized mannoside 3 yielded the desired dodecaglycosylated BR. $\left(\mathbf{R}^{2}\right)_{6}$. The structure of the central Borromeate was ascertained by NMR and mass spectrometry. The dodecaamine cage $\mathbf{C} \cdot\left(\mathbf{R}^{3}\right)_{\mathbf{1 2}}$ was synthesized by in situ reduction of the spontaneously self-organized imine assembly of trialdehyde $\mathbf{4}$ and ethylene diamine. Acylation of the formed cage with compound $\mathbf{5}$ yielded dodecaamide $\mathbf{C} \cdot\left(\mathbf{R}^{\mathbf{4}}\right)_{\mathbf{1 2}}$, from which the glycosylated $\mathbf{C} \cdot\left(\mathbf{R}^{5}\right)_{12}$ was obtained by CuAAC with compound $\mathbf{6}$. The fullerene was functionalized using a Bingel reaction between unfunctionalized fullerene and malonic ester 7 to obtain dodecasubstituted fullerene $\mathbf{F} \cdot\left(\mathbf{R}^{6}\right)_{12}$. Carbohydrate functionalization was performed through CuAAC between $\mathbf{F} \cdot\left(\mathbf{R}^{6}\right)_{12}$ and compound 6 to obtain dodecaglycosylated $\mathbf{F} \cdot\left(\mathbf{R}^{7}\right)_{12}$.
The obtained carbohydrate nanoplatforms $\mathbf{B R} \cdot\left(\mathbf{R}^{2}\right)_{\mathbf{6}}, \mathbf{C} \cdot\left(\mathbf{R}^{5}\right)_{\mathbf{1 2}}$, and $\mathbf{F} \cdot\left(\mathbf{R}^{7}\right)_{12}$ and monovalent reference $\mathbf{8}$ (see Fig. 4 ) were evaluated using QCM technology. This technology allowed us to monitor the binding event between ConA and the carbohydrate ligands in real time, providing additional details with respect to the binding kinetics and thermodynamics. ConA was selected owing to its established adoption in multivalency studies. ${ }^{12}$ QCM sensors were prepared from activated, carboxyl-terminated, self-assembled monolayers, to which ConA was attached by amide coupling. Unreacted groups were subsequently blocked by treatment with ethanolamine. Immobilization of ConA on the sensor surfaces resulted in frequency shifts $(\Delta F)$ of $\approx 50 \mathrm{~Hz}$, indicating a successful conjugation process (Fig. S1, ESI $\dagger$ ).

The binding event was monitored by injecting eight different concentrations of the respective samples, ranging from 1.56 to $200 \mu \mathrm{g} \mathrm{mL}{ }^{-1}$, over the ConA-functionalized sensors. This resulted in $\Delta F \mathrm{~s}$ ranging from $0 \mathrm{~Hz}$ for the lowest concentrations to $50 \mathrm{~Hz}$ for the highest concentrations. In parallel, the samples were injected over unfunctionalized sensors for correction for nonspecific binding. Regeneration of both sensors was performed after each sample analysis using a $10 \mathrm{mM}$ solution of glycine at $\mathrm{pH}$ 2.5. Sensor regeneration proved to be highly successful for nanoplatforms BR.( $\left.\mathbf{R}^{2}\right)_{\mathbf{6}}$ and $\mathbf{C} \cdot\left(\mathbf{R}^{5}\right)_{\mathbf{1 2}}$, whereas the surfaces after injection of fullerene $\mathbf{F} \cdot\left(\mathbf{R}^{7}\right)_{12}$ did not fully regenerate 
(Fig. S3, ESI $\dagger$ ). This can be explained by the increased hydrophobic interactions of the fullerene core with the self-assembled monolayer present on the sensors. However, since the surfaces remained unsaturated throughout the experiments, accurate binding data were still obtained.

From the obtained sensorgrams, a selection was made to eliminate sample injections that showed spikes and other factors that could interfere with proper fitting of the model. The selected datasets were then fitted with a 1:2 interaction model to accommodate for both possible binding modes: monovalent and multivalent binding. The fitted datasets were used to extract estimates of the kinetic and thermodynamic data including the association rate $\left(k_{\mathrm{a}}\right)$, the dissociation rate $\left(k_{\mathrm{d}}\right)$ and the dissociation constant $\left(K_{\mathrm{D}}\right)$. The obtained sensorgrams as well as the fitted datasets and estimated binding data are shown in Fig. 3. From the sensorgrams, it can clearly be seen that the dissociation rate of the icosahedrally glycosylated cage $C \cdot\left(\mathbf{R}^{\mathbf{5}}\right)_{\mathbf{1 2}}$ was significantly higher than those of the octahedrally substituted Borromeate BR. $\left(\mathbf{R}^{2}\right)_{\mathbf{6}}$ and fullerene $\mathbf{F} \cdot\left(\mathbf{R}^{7}\right)_{\mathbf{1 2}}$. As a result, the surface was almost fully regenerated after a $500 \mathrm{~s}$ dissociation time when treated with cage $\mathbf{C} \cdot\left(\mathbf{R}^{\mathbf{5}}\right)_{\mathbf{1 2}}$, whereas this was not the case for the
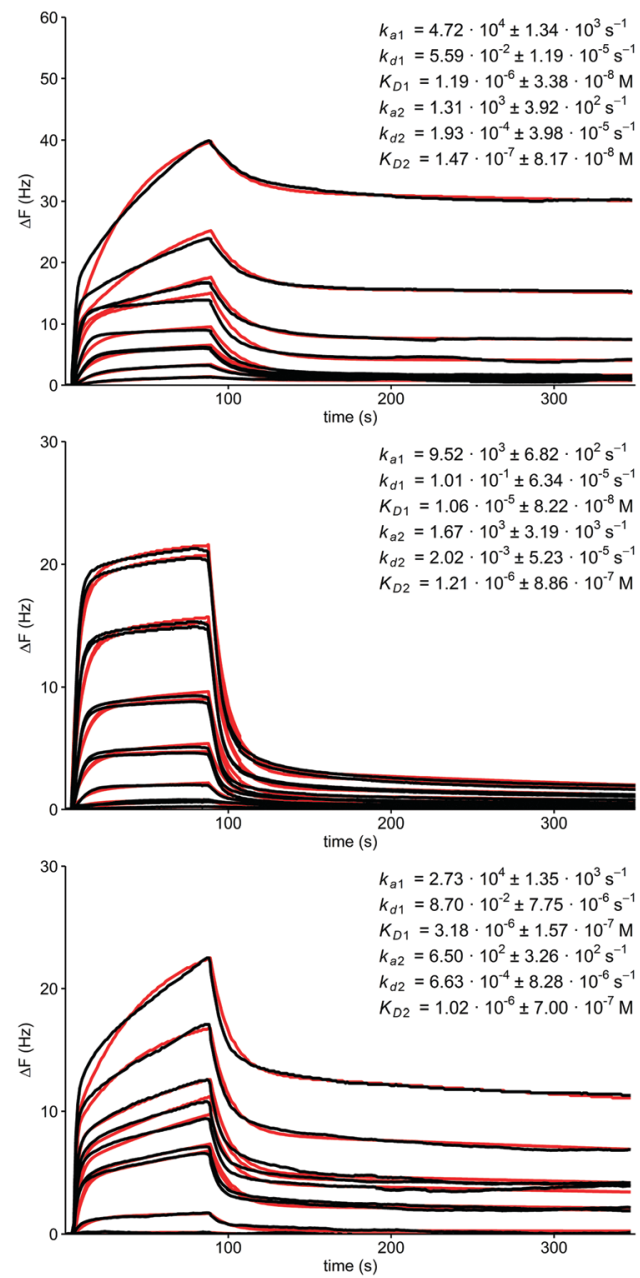

Fig. 3 Selected obtained sensorgrams (black curves) and fitted datasets (red curves) for nanoplatforms BR. $\left(\mathbf{R}^{2}\right)_{6}, \mathbf{C} \cdot\left(\mathbf{R}^{5}\right)_{12}$ and $\mathbf{F} \cdot\left(\mathbf{R}^{7}\right)_{12}$ together with estimated binding data. other two nanoplatforms. Another observation is that the sensorgram for cage $\mathbf{C} \cdot\left(\mathbf{R}^{\mathbf{5}}\right)_{\mathbf{1 2}}$ clearly shows two binding events, indicating monovalent and multivalent binding interactions. For Borromeate $\mathbf{B R} \cdot\left(\mathbf{R}^{\mathbf{2}}\right)_{\mathbf{6}}$ and fullerene $\mathbf{F} \cdot\left(\mathbf{R}^{7}\right)_{\mathbf{1 2}}$, the overall stronger binding obscures the visibility of two separate binding events and the stronger multivalent binding event was mainly observed. Overall, the estimated binding data show $K_{\mathrm{D}}$-values as low as $147 \mathrm{nM}$, $1.21 \mu \mathrm{M}$ and $1.02 \mu \mathrm{M}$ for Borromeate BR. $\left(\mathbf{R}^{2}\right)_{6}$, cage $\mathbf{C} \cdot\left(\mathbf{R}^{5}\right)_{12}$ and fullerene $\mathbf{F} \cdot\left(\mathbf{R}^{7}\right)_{\mathbf{1 2}}$, respectively. The weakest binding to ConA, as already apparent from the sensorgrams, was estimated for cage $\mathbf{C} \cdot\left(\mathbf{R}^{\mathbf{5}}\right)_{\mathbf{1 2}}$. However, the lower association rate combined with a lower dissociation rate resulted in a very similar affinity for fullerene $\mathbf{F} \cdot\left(\mathbf{R}^{7}\right)_{\mathbf{1 2}}$. In contrast, the larger Borromeate $\mathbf{B R} \cdot\left(\mathbf{R}^{\mathbf{2}}\right)_{\mathbf{6}}$ nanoplatform showed higher affinity towards ConA in consequence of a relatively high association rate and low dissociation rate. In terms of multivalency and cooperativity, ${ }^{13}$ regular chelation is inaccessible, and subsite chelation in combination with statistical and polyelectrolyte effects are expected to be the major contributors to the increased affinity observed in the nanoplatforms. In $\mathbf{C} \cdot\left(\mathbf{R}^{\mathbf{5}}\right)_{\mathbf{1 2}}$, potentially weaker subsite interactions may lead to the observed saturation, whereas the difference in the $K_{\mathrm{D}}$-value between the two nanoplatforms with octahedral ligand presentation may be a result of their difference in size and charge. Another explanation for this phenomenon can be the forced higher spatial distribution of carbohydrate ligands in fullerene $\mathbf{F} \cdot\left(\mathbf{R}^{7}\right)_{\mathbf{1 2}}$ due to substitution of the carbohydrate ligands on a cyclopropane motif.

To be able to assess the multivalency effect, the same experiment was performed for monovalent reference 8, as shown in Fig. 4. As the molecular weight of compound $\mathbf{8}$ is significantly lower in comparison to the nanoplatforms, the observed $\Delta F$ was considerably lower as reflected in the reduced accuracy of the fitted data. As clear saturation could be observed in the sensorgrams, saturation binding was determined instead of fitting model data. The obtained $K_{\mathrm{D}}$-value for compound $\mathbf{8}$ was estimated to be $109 \mu \mathrm{M}$. Due to the multivalency effect, the relative potency, i.e. the binding affinity per carbohydrate unit, increased by approximately 66-, 8- and 10-fold for Borromeate $\mathbf{B R} \cdot\left(\mathbf{R}^{2}\right)_{6}$, cage $\mathbf{C} \cdot\left(\mathbf{R}^{\mathbf{5}}\right)_{\mathbf{1 2}}$ and fullerene $\mathbf{F} \cdot\left(\mathbf{R}^{7}\right)_{\mathbf{1 2}}$, respectively.

In summary, using the toolbox provided by CDC we have demonstrated the synthesis of two novel highly ordered carbohydrate nanoplatforms BR. $\left(\mathbf{R}^{2}\right)_{\mathbf{6}}$ and $\mathbf{C} \cdot\left(\mathbf{R}^{\mathbf{5}}\right)_{\mathbf{1 2}}$. Using QCM technology, the binding affinity towards ConA could be elucidated and

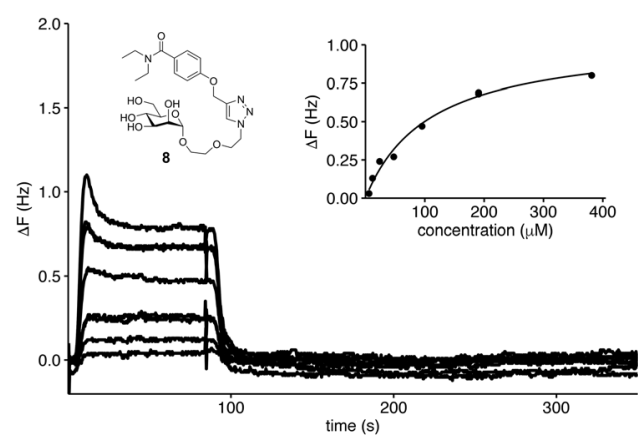

Fig. 4 Obtained sensorgrams for compound 8 . Inset: Saturation binding isotherm; estimated $K_{\mathrm{D}}=109 \pm 19 \mu \mathrm{M}$. 
compared to monovalent reference $\mathbf{8}$ and dodecaglycosylated fullerene $\mathbf{F} \cdot\left(\mathbf{R}^{7}\right)_{\mathbf{1 2}}$. Besides the multivalency effect, the results indicate a tendency towards stronger binding for the larger nanoplatform $\mathbf{B R} \cdot\left(\mathbf{R}^{2}\right)_{\mathbf{6}}$, with octahedral presentation of the ligands, as compared to scaffolds $\mathbf{F} \cdot\left(\mathbf{R}^{7}\right)_{\mathbf{1 2}}$ and $\mathbf{C} \cdot\left(\mathbf{R}^{\mathbf{5}}\right)_{\mathbf{1 2}}$, which show octahedral and icosahedral carbohydrate presentations, respectively. This effect is possibly due to more optimal local densities of carbohydrates on Borromeate BR. $\left(\mathbf{R}^{\mathbf{2}}\right)_{\mathbf{6}}$, in contrast to the higher spatial dispersion of carbohydrates in cage $\mathbf{C} \cdot\left(\mathbf{R}^{\mathbf{5}}\right)_{\mathbf{1 2}}$ and the smaller, more constrained fullerene $\mathbf{F} \cdot\left(\mathbf{R}^{\mathbf{7}}\right)_{\mathbf{1 2}}$. In conclusion, these results reveal the importance of the spatial presentation of carbohydrates for recognition events. It is also worth noticing that this report shows the first application of molecular Borromean rings in biomolecular recognition.

This project received funding from the European Union's Seventh Framework Programme for research, technological development and demonstration under grant agreement no. 289033.

\section{Notes and references}

1 A. Varki, R. D. Cummings, J. D. Esko, H. H. Freeze, P. Stanley and C. R. Bertozzi, et al., Essentials of Glycobiology, Cold Spring Harbor Laboratory Press, Cold Spring Harbor, 2009.

2 (a) S. Cecioni, A. Imberty and S. Vidal, Chem. Rev., 2015, 115, 525; (b) Y. M. Chabre and R. Roy, Adv. Carbohydr. Chem. Biochem., 2010, 63, 165; (c) J. J. Lundquist and E. J. Toone, Chem. Rev., 2002, 102, 555.

3 (a) N. Hao, K. Neranon, O. Ramström and M. Yan, Biosens. Bioelectron., 2016, 76, 113; (b) O. Ramström and M. Yan, Chem. - Eur. J., 2015, 21, 16310; (c) X. Chen, O. Ramström and M. Yan, Nano Res., 2014, 7, 1381; (d) A. Bernardi, J. Jiménez-Barbero, A. Casnati, C. De Castro, T. Darbre and F. Fieschi, et al., Chem. Soc. Rev., 2013, 42, 4709; (e) V. Wittmann and R. J. Pieters, Chem. Soc. Rev., 2013, 42, 4492; $(f)$ X. Wang, O. Ramström and M. Yan, Adv. Mater., 2010, 22, 1946.

4 A. Hirsch and O. Vostrowsky, Eur. J. Org. Chem., 2001, 829.

5 (a) M. Durka, K. Buffet, J. Iehl, M. Holler, J.-F. Nierengarten and S. P. Vincent, Chem. - Eur. J., 2012, 18, 641; (b) M. Sánchez-Navarro, A. Muñoz, B. M. Illescas, J. Rojo and N. Martín, Chem. - Eur. J., 2011, 17, 766; (c) S. Cecioni, V. Oerthel, J. Iehl, M. Holler, D. Goyard and J.-P. Praly, et al., Chem. - Eur. J., 2011, 17, 3252; (d) J.-F. Nierengarten, J. Iehl, V. Oerthel, M. Holler, B. M. Illescas and A. Munoz, et al., Chem. Commun., 2010, 46, 3860.
6 (a) Y. Zhang and M. Barboiu, Chem. Rev., 2016, 116, 809; (b) J. M. Lehn, Angew. Chem., Int. Ed., 2015, 54, 3276; (c) L. Hu, F. Schaufelberger, B. J. J. Timmer, M. Abellán-Flos and O. Ramström, Kirk-Othmer Encycl. Chem. Technol., 2014, 1; (d) Y. Jin, C. Yu, R. J. Denman and W. Zhang, Chem. Soc. Rev., 2013, 42, 6634; (e) Y. Zhang, L. Hu and O. Ramström, in Supramolecular Systems in Biomedical Fields, ed. H.-J. Schneider, RSC Publishing, 2013, p. 397; $(f)$ Constitutional Dynamic Chemistry, ed. M. Barboiu, Springer Verlag, Heidelberg, 2012; $(g)$ M. Sakulsombat, Y. Zhang and O. Ramström, Top. Curr. Chem., 2012, 322, 55; (h) E. Moulin, G. Cormos and N. Giuseppone, Chem. Soc. Rev., 2012, 41, 1031; (i) Dynamic Combinatorial Chemistry: In Drug Discovery, Bioorganic Chemistry, and Materials Science, ed. B. L. Miller, John Wiley \& Sons, Inc., 2010; $(j)$ Dynamic Combinatorial Chemistry, ed. S. Otto and J. N. H. Reek, Wiley-VCH Verlag GmbH \& Co. KGaA, Weinheim, 2010. 7 Z. He, W. Jiang and C. A. Schalley, Chem. Soc. Rev., 2015, 44, 779.

8 (a) C. D. Pentecost, N. Tangchaivang, S. J. Cantrill, K. S. Chichak, A. J. Peters and J. F. Stoddart, J. Chem. Educ., 2007, 84, 855; (b) S. J. Cantrill, K. S. Chichak, A. J. Peters and J. F. Stoddart, Acc. Chem. Res., 2005, 38, 1; (c) A. J. Peters, K. S. Chichak, S. J. Cantrill and J. F. Stoddart, Chem. Commun., 2005, 3394; (d) K. S. Chichak, S. J. Cantrill, A. R. Pease, S.-H. Chiu, G. W. V. Cave and J. L. Atwood, et al., Science, 2004, 304, 1308.

9 (a) S. I. Swamy, J. Bacsa, J. T. A. Jones, K. C. Stylianou, A. Steiner and L. K. Ritchie, et al., J. Am. Chem. Soc., 2010, 132, 12773; (b) T. Tozawa, J. T. A. Jones, S. I. Swamy, S. Jiang, D. J. Adams and S. Shakespeare, et al., Nat. Mater., 2009, 8, 973.

10 (a) J. L. Culshaw, G. Cheng, M. Schmidtmann, T. Hasell, M. Liu and D. J. Adams, et al., J. Am. Chem. Soc., 2013, 135, 10007; (b) C. R. Yates, D. Benítez, S. I. Khan and J. F. Stoddart, Org. Lett., 2007, 9, 2433; (c) K. S. Chichak, A. J. Peters, S. J. Cantrill and J. F. Stoddart, J. Org. Chem., 2005, 70, 7956.

11 (a) C. I. Cheng, Y.-P. Chang and Y.-H. Chu, Chem. Soc. Rev., 2012, 41, 1947; (b) O. Norberg, I. H. Lee, T. Aastrup, M. Yan and O. Ramström, Biosens. Bioelectron., 2012, 34, 51; (c) O. Norberg, L. Deng, T. Aastrup, M. Yan and O. Ramström, Anal. Chem., 2011, 83, 1000; (d) O. Norberg, L. Deng, M. Yan and O. Ramström, Bioconjugate Chem., 2009, 20, 2364; (e) Z. Pei, H. Anderson, T. Aastrup and O. Ramström, Biosens. Bioelectron., 2005, 21, 60.

12 (a) J. Zhou, N. Hao, T. De Zoyza, M. Yan and O. Ramström, Chem. Commun., 2015, 51, 9833; (b) N. Kong, M. R. Shimpi, O. Ramström and M. Yan, Carbohydr. Res., 2015, 405, 33; (c) M. J. Chmielewski, E. Buhler, J. Candau and J. M. Lehn, Chem. - Eur. J., 2014, 20, 6960; (d) E. Mahon, Z. Mouline, M. Silion, A. Gilles, M. Pinteala and M. Barboiu, Chem. Commun., 2013, 49, 3004.

13 (a) C. A. Hunter and H. L. Anderson, Angew. Chem., Int. Ed., 2009, 48, 7488; (b) L. L. Kiessling, T. Young, D. T. Gruber and H. K. Mortell, Glycoscience: Chemistry and Chemical Biology, Springer, Berlin, Heidelberg, 2008, p. 2483; (c) M. Mammen, S. K. Choi and G. M. Whitesides, Angew. Chem., Int. Ed., 1998, 37, 2755. 